\title{
High School Science Experiences Associated to Mastery Orientation Towards Learning
}

\author{
Katrina Velez*, Geoff Potvin* and Zahra Hazari ${ }^{\dagger}$ \\ ${ }^{*}$ Department of Physics, and STEM Transformation Institute, Florida International University, $11200 \mathrm{SW} 8^{\text {th }}$ \\ St., Miami, FL 33199 \\ ${ }^{\dagger}$ Department of Teaching \& Learning, Department of Physics, and STEM Transformation Institute, Florida \\ International University, 11200 SW $8^{\text {th }}$ St., Miami, FL 33199
}

\begin{abstract}
An individual's motivational orientation can influence their views on their academic potential and the actions they take to achieve it. In particular, a mastery orientation towards learning has been shown to positively influence the scientific productivity of career scientists and is associated to desirable learning outcomes. This study examines which high school physics experiences (including teacher practices and other classroom experiences) are associated to changes in students' mastery orientation using exploratory factor analysis and regression on nationally-representative survey data taken from students enrolled in introductory English courses in the U.S. during the Fall of 2011. The implications of these findings for the improvement of the teaching of physics will be discussed.
\end{abstract}

Keywords: Goal orientation, career choice

PACS: $01.30 . \mathrm{Cc}, 01.40 . \mathrm{Fk}$

\section{INTRODUCTION}

Individual motivations have been studied across a broad spectrum of contexts including student motivation within classroom settings $[1,2,3,4,5,6,7,8]$. Motivations provide a drive to action which influence not only the effort an individual may put forth to achieve a goal, but also influence the types of goals undertaken. In an educational context, a student's motivations may influence their self-assessment of their own academic potential as well as choices they make in their academic career. However, motivations are not fixed and different educational experiences can help facilitate different shifts in motivations, e.g from being "unmotivated" to "motivated" in a general sense. More specifically, educational experiences could also facilitate a shift towards being motivated towards learning for oneself rather than for extrinsic rewards such as grades, awards, etc. With the overwhelming emphasis on extrinsic performance in schools, it is important to understand what experiences and practices may help shift students towards a more intrinsic pursuit of learning.

A fruitful framework for understanding motivation has been that of goal orientation $[2,4,5]$. Two types of goal orientation in particular have been articulated. The first is a mastery orientation, in which a student is focused on his/her own competence and is motivated to accomplish a learning goal in order to gain mastery of the material. Considerable evidence has supported positive effects when students adopt mastery-oriented goals. For example, having a mastery orientation is advantageous given a high degree of challenge or when processing difficult concepts [9]. The second is a performance orientation in which an individual is motivated to demonstrate their performance or abilities to others. One concern connected to this latter orientation is that school environments encouraging performance measures can increase the academic performance of some students, but can diminish student motivation overall [9].

In previous work $[10,11]$, we studied over 3,000 PhDholding scientists in physics and chemistry and identified those individuals who could be said to hold a mastery (or "learning") orientation (based on the reasons they chose to attend graduate school). These participants were recruited through their association to a pair of professional scientific societies, and were broadly representative of the U.S. population of practicing, PhD-holding physicists and chemists (including academics, industrial scientists, etc). We examined the output of these individuals and found that they had been more productive as scientists in terms of the number of primary/first-author publications they had published and the grant funding they had secured. By contrast, those individuals who could be identified as holding a performance orientation were no more productive than average. These results strongly suggested that an individual's mastery orientation was beneficial for them as researchers, and that educators would do well to try to cultivate such attitudes in their students. However, a limitation of this earlier work was that, due to the nature of the study and data collected, we could say little about which experiences, earlier in an individual's education, could help to develop a mastery 


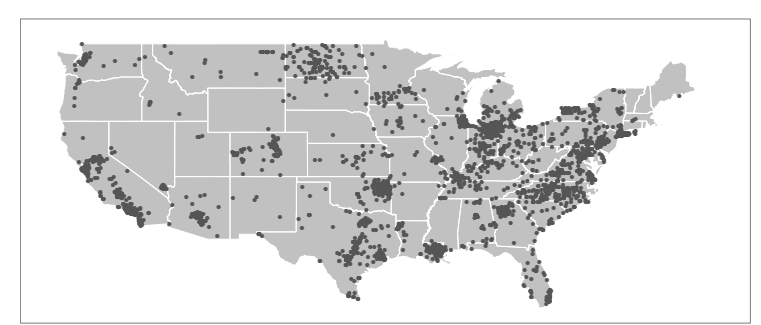

FIGURE 1. Map representing respondents' home ZIP codes. Each dot represents a single reported ZIP code, not an individual student. Created with the "ggplot2"[12] and "maptools" [13] packages.

orientation. Thus, in the current paper, we pursued the following research question in the context of a new research study that collected data from students at the high school-to-college transition:

- Which high school physics experiences are associated to improvements or decreases in students' mastery orientation?

\section{DATA COLLECTION AND METHODOLOGY}

To address the research question, exploratory factor analysis followed by multiple linear regression was applied to data drawn from the Sustainability and Gender in Engineering (SaGE) Survey (NSF Grant Number 1036617). This survey (http://stem.fiu.edu/sage) was conducted in the Fall of 2011 by surveying students in regular college introductory English courses at 50 institutions (including both 2- and 4-year schools). The participating schools were recruited from a stratified random sample of a comprehensive list of all U.S. post-secondary institutions. The list was stratified based on the relative number of students at 2- and 4-year institutions and on institution size (avoiding over- or under-representing the numerous, small liberal arts colleges). In surveying regular college English classes, a typical mandatory course, it was possible to gather data from a nationally-representative sample of students that includes both STEM and non-STEM majors. In total, 6772 students returned surveys, with some representation from each of the 50 recruited institutions (100\% institutional response rate). Figure 1 provides a visualization of the national representativeness of the student respondents.

The SaGE survey included items that probed students' high school experiences (particularly, their math and science classes), their career intentions and career outcome expectations, their attitudes and beliefs about the role of science and engineering in the modern world, their self- ascribed science and math identities, and demographic information.

To address the research question, firstly, a set of responses to a series of 15 anchored, 5-point items describing various career outcome expectations ("How important are the following factors for your future career satisfaction?") were analyzed using exploratory factor analysis. Some examples of the 15 items include "Making money", "Solving societal problems", and "Working with people". A promax rotation was utilized, recognizing the possibility that the underlying factors to these outcome expectations may be intercorrelated. The result was the identification of three items which loaded onto one factor, identified as mastery orientation, including the items "Inventing/designing things", "Developing new knowledge and skills", and "Applying math and science". The loadings of these three items on the mastery orientation factor were $0.78,0.45$, and 0.51 , respectively, and this single factor explains $10 \%$ of the cumulative variance of all the outcome expectation items. Note that three other factors were also identified in this analysis, but they were all associated to other orientations/expectations (e.g. a factor associated to purely socio-economic considerations, etc.).

Secondly, the mastery orientation factor was used as the outcome in a multiple regression model, which was constructed to directly assess our research question. A set of demographic controls were tested, including race, ethnicity, gender, an Academic Index variable which assessed the totality of students' prior academic performances (including their physics grades), and various aspects of respondents' family support of science and mathematics. In addition to these, several variables related to students' last high school physics course were tested, including teacher practices (e.g. regularity of lecturing), the type of resources available in the classroom, and the types and nature of classroom activities and test questions which were posed to students. Results are reported in Table 1 . Throughout this analysis, $\alpha$, the maximum allowed chance of Type I error, was fixed at $5 \%$. All data analysis was conducted using R [14] and utilized the "car" [15] and "QuantPsyc" [16] packages.

\section{RESULTS}

In total, the final regression model accounts for $16.3 \%$ of the variance in mastery orientation, as measured by the adjusted $\mathrm{R}^{2}$. Note that gender was a significant predictor for mastery orientation $(p<0.001)$, with males indicating a higher level of mastery orientation on average than women. Identifying as being of an Asian descent other than South or East Asian was a positive predictor of mastery orientation $(p<0.05)$. Identifying as Caucasian/white, East Asian, or being of Hispanic ori- 
TABLE 1. Regression model predicting mastery orientation. $N=2421$, adj. $R^{2}=0.163$.

\begin{tabular}{lcccc}
\hline Variable & Estimate & Std. Error & $\beta$ & Sig. $^{\dagger}$ \\
\hline Intercept & 0.4773 & 0.0374 & - & $* * *$ \\
\hline Gender - Male (compared to Female) & 0.0387 & 0.0082 & 0.0899 & $* * *$ \\
Racial group - Other Asian & 0.0598 & 0.0244 & 0.0476 & $*$ \\
Racial group - Caucasian or white & -0.0774 & 0.0103 & -0.1644 & $* * *$ \\
Racial group - East Asian & -0.0584 & 0.0199 & -0.0588 & $* *$ \\
Ethnicity - Hispanic & -0.0295 & 0.0120 & -0.0501 & $*$ \\
Year of college enrollment & 0.0209 & 0.0072 & 0.0554 & $* *$ \\
Academic performance index (0...1) & 0.0796 & 0.0235 & 0.0661 & $* * *$ \\
\hline Family science interest - it was a diversion or hobby & 0.0363 & 0.0098 & 0.0755 & $* * *$ \\
Family science interest - it was for a better career & 0.0460 & 0.0091 & 0.1041 & $* * *$ \\
Family science interest - it was not an interest & -0.0378 & 0.0086 & -0.0841 & $* * *$ \\
Family math interest - it was a diversion or hobby & 0.0227 & 0.0101 & 0.0449 & $*$ \\
Family math interest - it was for a better career & 0.0432 & 0.0090 & 0.0970 & $* * *$ \\
Family math interest - they arranged for tutoring & -0.0319 & 0.0095 & -0.0654 & $* * *$ \\
\hline Frequency of lecturing (compared to "Never"): & & & & \\
"Rarely" & -0.1013 & 0.0327 & -0.0833 & $* *$ \\
$\quad$ "Monthly" & -0.1012 & 0.0320 & -0.0909 & $* *$ \\
"Weekly" & -0.0692 & 0.0263 & -0.1217 & $* *$ \\
"Daily" & -0.0642 & 0.0247 & -0.1355 & $* *$ \\
Frequency of doing individual work in class (compared to "Never"): & & & \\
"Rarely" & 0.0669 & 0.0278 & 0.0795 & $*$ \\
"Monthly" & 0.0223 & 0.0278 & 0.0290 & n/s \\
"Weekly" & 0.0602 & 0.0252 & 0.1326 & $*$ \\
"Daily" & 0.0582 & 0.0246 & 0.1349 & $*$ \\
Level of memorization required in physics (0...4) & 0.0076 & 0.0038 & 0.0385 & $*$ \\
Physics questions required new insight and creativity & 0.0297 & 0.0085 & 0.0683 & $* * *$ \\
Other classmates' interest in physics (0...4) & 0.0220 & 0.0034 & 0.1294 & $* * *$ \\
\hline
\end{tabular}

${ }^{\dagger} \mathrm{n} / \mathrm{s}$ : not significant, *: $p<0.05, * *: p<0.01: * * *: p<0.001$

gin were all negative predictors $(p<0.001 ; p<0.01$; $p<0.05$, respectively) of mastery orientation. Students' year in college was positively associated with mastery orientation ( $\mathrm{p}<0.01)$, indicating an increase in students' mastery orientation as they move further away from high school.

In terms of factors related to family support for science and mathematics, several were significantly related to mastery orientation. Students who reported that their family interest in science was that it was "a diversion or hobby" or "a way to have a better career" were higher on the mastery orientation scale (both $p<0.001$ ), whereas those who reported science was not a family interest were lower on the mastery orientation scale $(p<0.001)$. Turning to math, those who reported their family interest in math was as "a diversion or hobby" or as "a way to have a better career" showed greater mastery orientation on average ( $p<0.05 ; p<0.001$, respectively), while those reporting their families arranged for tutoring $(p<0.001)$ showed lower mastery orientation. Lastly, the Academic Index of prior performance (across all domains including their physics performance) was a significant, positive predictor of mastery orientation $(p<0.001)$.
Turning to the variables of greatest interest - those assessing students' prior experience in physics classrooms - several factors were significant predictors of mastery orientation. Importantly, students who reported a greater frequency of lecturing (at each level above "Never") indicated lower mastery orientation, on average $(p<0.01)$. This result provides further cautionary evidence against the over-use of lecturing as a pedagogical practice.

Students indicating that they did individual work in class more frequently (for three of the four levels above "Never") had higher levels of mastery orientation ( $p<$ 0.05 ). Though reformed pedagogies often focus on group work and/or whole class participation as a means to more effective learning (and we do not dispute this), this result may be an indicator that those students who have had greater opportunity to engage their own ideas and conceptions as they learn physics material also learn to value the learning process itself, a result which is consistent with other work [17]. Similarly, students who indicated that their physics class focused more on memorization were higher on the mastery orientation scale $(p<0.05)$. While memorization is rarely thought of as being valuable to effective learning, this result (which is admittedly a small effect and significant only at the 5\% level) may 
be indicative that more impactful physics classes covered a greater amount of ultimately interesting physics ideas (requiring more memorization), and those students were influenced in their learning orientation as a result. Further investigation will be required to understand this.

Interestingly, two other factors proved significant in the regression model. Students who reported that they had to answer questions that "required new insight and creativity" were higher on the mastery orientation scale $(p<0.001)$. This finding gives some credence to the idea that there are benefits for students who are challenged to use their originality and higher-level cognitive skills: in this case, the benefit is that they value the learning process and their own understanding more greatly. Lastly, students were asked to report on the level of interest in physics of their classmates: those who reported their peers to have higher interest were also higher on the mastery orientation scale $(p<0.001)$. This result may provide evidence for the diffusive benefits of an interested, engaged group of peers.

\section{DISCUSSION}

The results of this work indicate that what happens in a physics classroom may provide benefits for students that go well beyond the direct learning outcomes of the course. In this case, we found several classroom experiences and practices that were associated to differences in students' mastery orientation, a broad construct that is not context (or content) specific. Thus, physics educators should find encouragement that their actions may positively benefit students in myriad ways. To reiterate, in prior work we found that a mastery orientation towards learning is a positive predictor of career scientists' research output $[10,11]$; the current work shows that classroom experiences may help to generate this beneficial attitude towards learning. Rather than treating individuals' goal orientation as a fixed trait ("you either have it or you don't"), educators would better serve students to cultivate productive motivations such as mastery orientation through their teaching practice.

Some limitations of this work should be kept in mind. Firstly, as the data was collected in a cross-sectional design, the results we have found here are correlational in nature; the causal mechanisms (including the directionality of cause and effect) underlying these results should be studied further. Second, as mentioned above, the maximum allowed probability of Type I error has been set at 5\% throughout this work: this introduces the possibility that one or more of these effects (particularly those factors significant only at the 5\% level) may be Type I error. In future work, we plan to expand this analysis to consider the effects of classroom biology and chemistry classes on mastery orientation which may elucidate common themes (as well as some differences) between science subject areas.

\section{ACKNOWLEDGEMENTS}

Thanks to the SaGE participants and the rest of the SaGE team especially Tyler Scott, Leidy Klotz, Allison Godwin, and Robynne Lock. This material is based on work supported by the National Science Foundation under Grant No. 1036617. Any opinions, findings, conclusions, or recommendations do not necessarily reflect the views of the National Science Foundation.

\section{REFERENCES}

[1] E. Deci, and R. Ryan, "A motivational approach to self: integration in personality," in Perspectives on motivation, edited by R. Dienstbier, Nebraska Symposium on Motivation 38, University of Nebraska Press, Lincoln, 1991, pp. 237-288.

[2] C. Ames, J. Ed. Psych. 84, 261-271 (1992).

[3] P. R. Pintrich, R. W. Marx, and R. A. Boyle, Rev. Ed. Res. 63, 167-199 (1993).

[4] T. C. Urdan, and M. L. Maehr, Review of educational research 65, 213-243 (1995).

[5] C. A. Wolters, S. L. Yu, and P. R. Pintrich, Learn. Indiv. Diff. 8, 211-238 (1996).

[6] R. M. Ryan, and E. L. Deci, Am. Psych. 55, 68-78 (2000).

[7] R. P. DeShon, J. Z. Gillespie, et al., Journal of Applied Psychology 90, 1096 (2005).

[8] J. L. Smith, C. Sansone, and P. H. White, Journal of Educational Psychology 99, 99 (2007).

[9] J. L. Meece, E. M. Anderman, and L. H. Anderman, Annu. Rev. Psychol. 57, 487-503 (2006).

[10] Z. Hazari, G. Potvin, R. H. Tai, and J. Almarode, Phys. Rev. ST Phys. Educ. Res. 6, 010107 (2010).

[11] Z. Hazari, G. Potvin, R. H. Tai, and J. T. Almarode, Journal of College Science Teaching 41, 90-98 (2012).

[12] H. Wickham, ggplot2: elegant graphics for data analysis, Springer New York, 2009, ISBN 978-0-387-98140-6, URL http://had.co.nz/ggplot2/book.

[13] R. Bivand, and N. Lewin-Koh, maptools: Tools for reading and handling spatial objects (2014), URL http://CRAN.R-project.org/package=maptools, $r$ package version $0.8-30$.

[14] R Core Team, R: A Language and Environment for Statistical Computing, R Foundation for Statistical Computing (2014), URL http://www.R-project.org/.

[15] J. Fox, and S. Weisberg, An R Companion to Applied Regression, Sage, Thousand Oaks CA, 2010, second edn., URL http://socserv.socsci.mcmaster.ca/jfox/Books/ Companion.

[16] T. D. Fletcher, QuantPsyc: Quantitative Psychology Tools (2010), URL http://CRAN.R-project.org/package= QuantPsyc, $\mathrm{r}$ package version 1.4.

[17] A. Bandura, Social foundations of thought and action: A social cognitive theory., Prentice-Hall, Inc, 1986. 